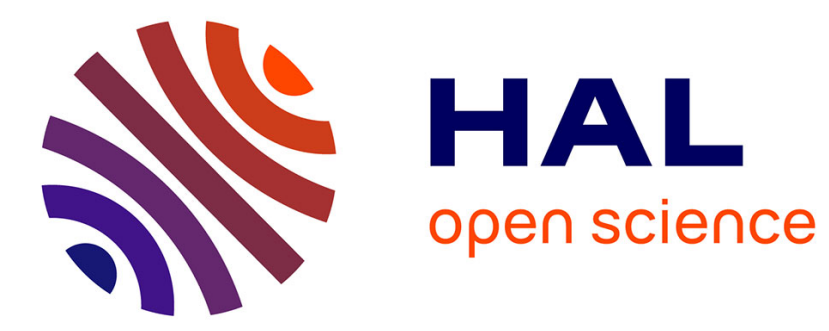

\title{
Effect of internal stresses and dislocation features on the magnetic properties of soft ferromagnetic materials
}

\author{
Olivier Hubert, E. Hug, I. Guillot, M. Clavel
}

\section{To cite this version:}

Olivier Hubert, E. Hug, I. Guillot, M. Clavel. Effect of internal stresses and dislocation features on the magnetic properties of soft ferromagnetic materials. Journal de Physique IV Proceedings, 1998, Soft Magnetic Materials 13, 08 (PR2), pp.Pr2-515 - Pr2-518. 10.1051/jp4:19982119 . hal-01575644

\section{HAL Id: hal-01575644 \\ https://hal.science/hal-01575644}

Submitted on 21 Aug 2017

HAL is a multi-disciplinary open access archive for the deposit and dissemination of scientific research documents, whether they are published or not. The documents may come from teaching and research institutions in France or abroad, or from public or private research centers.
L'archive ouverte pluridisciplinaire HAL, est destinée au dépôt et à la diffusion de documents scientifiques de niveau recherche, publiés ou non, émanant des établissements d'enseignement et de recherche français ou étrangers, des laboratoires publics ou privés. 


\title{
Effect of internal stresses and dislocation features on the magnetic properties of soft ferromagnetic materỉals
}

\author{
O. Hubert, E. Hug, I. Guillot and M. Clavel \\ LG2mS, UPRESA 6066 du CNRS, Université de Technologie de Compiègne, \\ Centre de Recherches de Royallieu, BP. 20529, 60205 Compiègne cedex, France
}

\begin{abstract}
This paper deals with the evolution of the magnetic anisotropy of non oriented $3 \%$ SiFe alloys plastically strained at various plastic strain levels $\left(\varepsilon_{\mathrm{p}}=0.5 \%\right.$ / 3.6\% / 9.8\%). The magnetization characteristics have been investigated for a $50 \mathrm{~Hz}$ sinusoidal magnetic field and under quasistatic excitation conditions $(0.1 \mathrm{~Hz})$, along the direction of deformation and in the crossing corresponding direction (i.e. $0^{\circ}$ for the $90^{\circ}$ strained pecimen and so on). Microstructural observations of the dislocation features for each sample are argued in this work. These experiments show that the magnetic properties markedly deteriorate when measurements are carried out in the direction of the applied stress. This phenomenon is less sensitive perpendicular to this applied stress. This plastically induced magnetic anisotropy remains quite constant whatever the plastic strain level. The influence of the kinematic stress level and the distribution of the dislocation features on magnetic properties is discussed.
\end{abstract}

\section{INTRODUCTION}

Non Oriented (NO) $3 \% \mathrm{SiFe}$ alloys are generally considered to be magnetically isotropic. However, it has been shown in a recent paper [1] that the magnetic properties evolve after the straining : the strengthening gives rise to a sensible magnetic anisotropy. The latter had been correlated with the presence of internal stresses linked to the plastic deformation. In the present paper, the influence of three other plastic strain levels on the plastic induced anisotropy of the magnetic properties is investigated. In addition, microstructural observations of the dislocation features have been performed for each sample. The influence of these parameters on the magnetic properties of the material is discussed.

\section{EXPERIMENTAL PROCEDURE}

Experiments have been carried out with an industrial NO 3\% SiFe alloy (0.5mm thick). Samples have been previously annealed before testing [2]. Magnetic measurements have been performed on samples (20x20 mm) which have been cut from the unstrained laminations and from the middle of the tensile test specimens previously strained at various plastic deformation levels. Magnetic characteristics have been investigated along the rolling (RD) and the tranverse (TD) directions by means of a suitable experimental system of measurements [3]. A quasistatic excitation $(\mathrm{f}=0.1 \mathrm{~Hz})$ and a $50 \mathrm{~Hz}$ sinusoidal magnetic field have been used. Tensile tests have been carried out at room temperature and constant strain rate. The plastic strain levels have been chosen in order to develop different microstructural states $[4]: \varepsilon_{\mathrm{p}}=0.5 \%$ (isotropic distribution of dislocations), $\varepsilon_{\mathrm{p}}=3.6 \%$ (formation of dislocation clusters) and $\varepsilon_{\mathrm{p}}=9.8 \%$ (formation of dislocation tangles). Microstructural observations of the dislocation features have been investigated on each sample. Thin foils have been taken from strained specimen and the substructure was observed by Transmission Electronic Microscopy.

\section{EXPERIMENTAL RESULTS}

\subsection{Magnetization characteristics at $50 \mathrm{~Hz}$}

Unstrained specimens exhibit a weak anisotropy of their initial magnetic properties (Fig. 1-b). Plastic strain is applied along RD or TD in order to study the plastic anisotropy of the magnetic properties of the material. The magnetic measurements are then implemented along either the tensile or cross direction. 

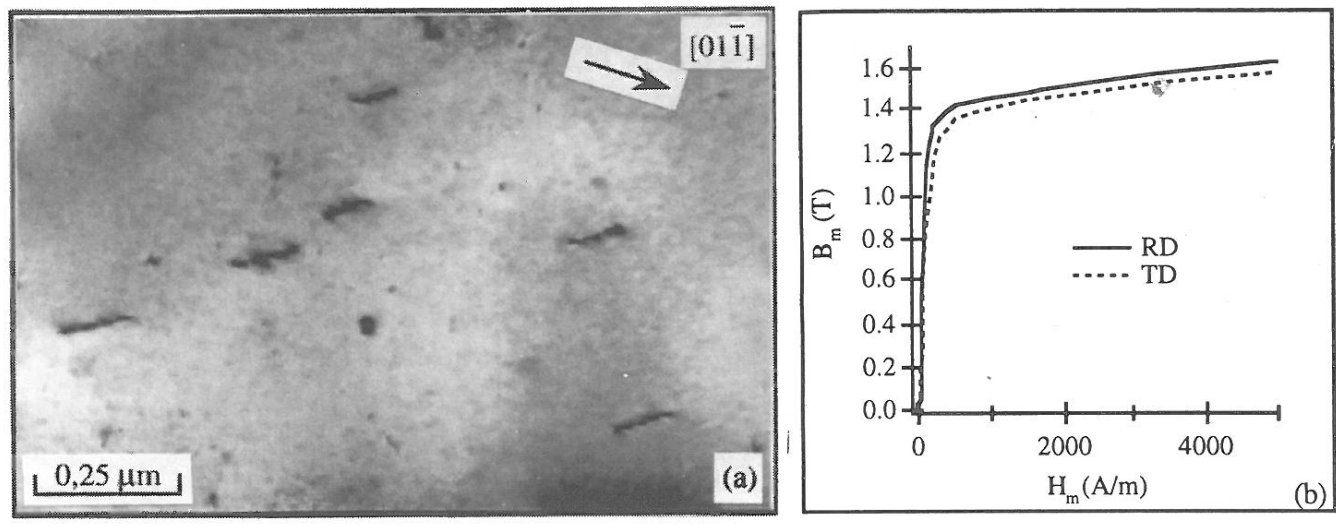

Table 1

Magn. measurement along RD

$\mathrm{H}_{\mathrm{c}}(\mathrm{RD})=43 \mathrm{~A} / \mathrm{m}$

Magn. measurement along TD

$H_{c}(T D)=60 \mathrm{~A} / \mathrm{m}$

Figure 1: Dislocation arrangement (a), corresponding magnetization curves ( $f=50 \mathrm{~Hz})(b)$ and coercive field strengths $(\mathrm{f}=0.1 \mathrm{~Hz})($ Table 1$)$ for an annealed specimen.

The change in the magnetization curves is shown in figures 2-d/i. The outcome of the experiments generalizes our previous results to other plastic strain levels [1]. The magnetic properties markedly deteriorate when measurements are carried out in the direction of the applied stress whatever the plasticstrain level (see also [5]). Crossing experiments indicate an attenuated effect of the plastic strain on the magnetic properties. Clearly, the decay of the magnetic properties along RD is more important with an applied stress lying along $\mathrm{RD}$ than along TD. The magnetic properties along TD behave similarly : the decay is more sensible with the applied stress parallel to TD. This effect is slightly less pronounced for magnetic measurements along the transverse direction. With an increasing plastic deformation, the magnetic properties deteriorate drastically. This effect is important in the first stages of the deformation $[0-0.5 \%]$. Next, the plastically induced magnetic anisotropy tends to increase very slowly from $0.5 \%$ to $9.8 \%$.

\subsection{Magnetization characteristics and coercive field strength at $0.1 \mathrm{~Hz}$}

Quasistatic experiments have been carried out with frequency of $0.1 \mathrm{~Hz}$ in order to obtain the various hysteresis parameters. The first magnetization curves behave similarly to the magnetic characteristics obtained with $\mathrm{f}=50 \mathrm{~Hz}$ and various strains : a strong magnetic deterioration with plastic deformation is observed, with a magnetic anisotropy of the same level. The coercive field strength $H_{c}$ exhibits a sensible initial anisotropy (Fig. 1 Table 1). The plastic strain strongly increases the values of $H_{c}$, up to three times the initial values for $\varepsilon_{\mathrm{p}}=3.6 \%$ (Fig. 2 Tables 2-3). Nevertheless, measurements carried out in the crossing direction of the applied stress give weaker values of the coercive field strength.

\subsection{Mechanical behaviour of the alloy and internal stresses}

The study of internal stresses which may exist inside the sample after strengthening required plastic fatigue experiments [1]. The results highlighted a strong kinematic strengthening behaviour of the material which is representative of strong internal and long range stresses in the deformed sample. This "Baushinger effect" [6] suddenly appears for the first stages of the plastic strain.

\subsection{Dislocation substructures}

The unstrained NO Fe-3\%Si B.C.C. matrix is characterized by a very low density of dislocations (Fig. 1-a). For $\varepsilon_{\mathrm{p}}=0.5 \%$ the dominant features are long screw dislocations with some cups and very few debris (Fig. 2-a). The bowing of dislocations is evidenced at $\varepsilon_{\mathrm{p}}=3.6 \%$ (Fig. 2-b) and the densities of debris increased. These debris are in the form of small or elongated loops created behind the jogged screw dislocations. The figure 2-c shows the substructure at $\varepsilon_{p}=9.8 \%$. At this stage heterogeneous substructures are already constituted. These heterogeneous substructures correspond to bundles of dislocations separated by regions of relatively low density. Contrast experiments have shown that bundles are generally composed of dislocation loops with primary Bürgers vector. 


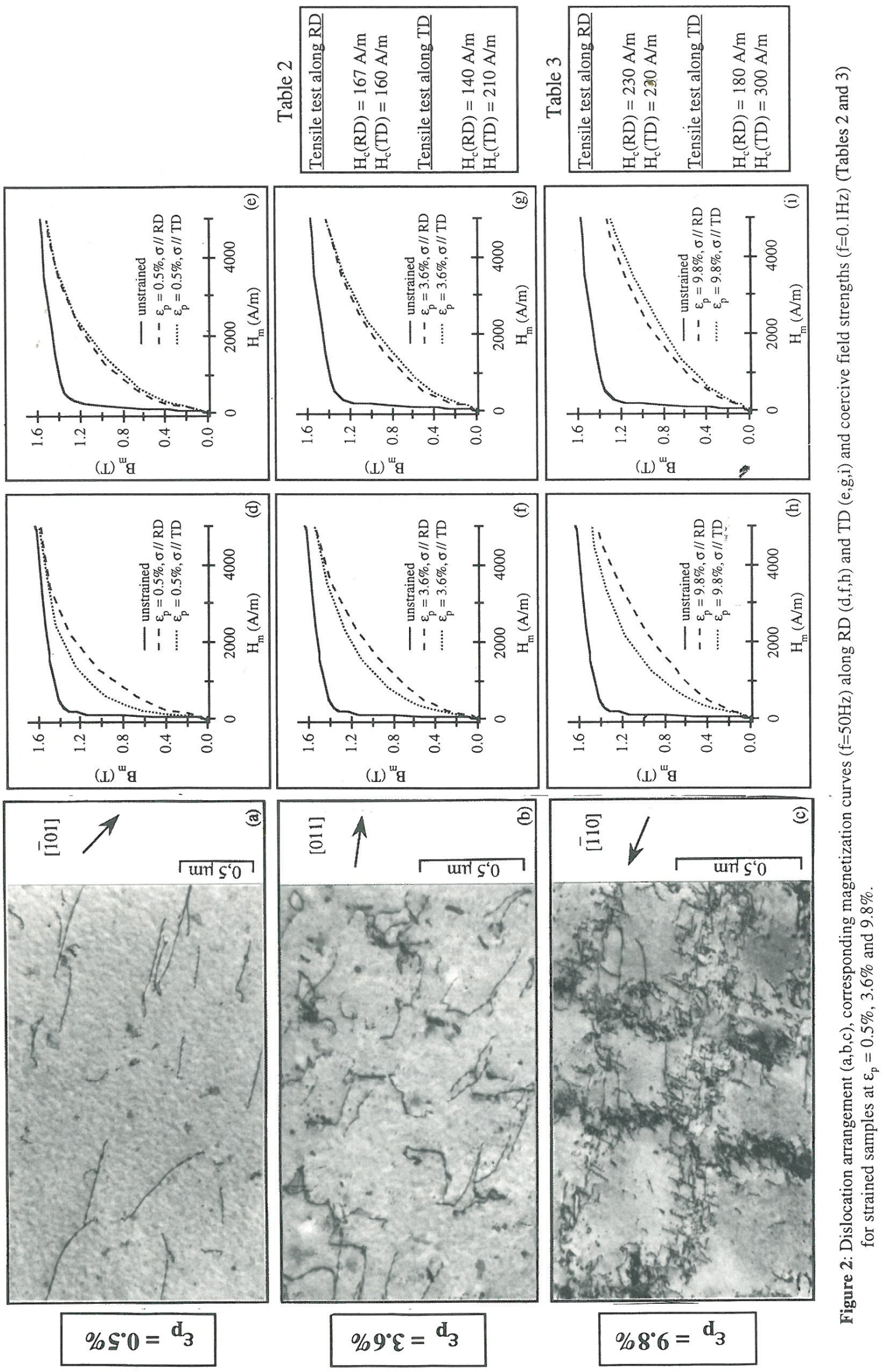




\section{DISCUSSION}

The degradation of the magnetic properties of $\mathrm{NO} 3 \% \mathrm{SiFe}$ alloys with plastic strain results from two effects which cannot be easily separated : a first one representative of the metallurgical defects and a second one due to the internal stresses which exist in the sample after the plastic straining.

The small dislocation clusters and tangles act as pinning centers for the magnetic domain walls. $\mathrm{H}_{\mathrm{c}}$ is representative of the irreversible changes of magnetization due to pinning/unpinning of the magnetic domain walls against metallurgical defects [5],[7],[8]. As a result, $H_{c}$ rises with plastic strain and the first magnetization curves are strongly modified. Moreover, the growth of $\mathrm{H}_{c}$ is a function of the angle between magnetic field and applied stress directions. The evolution of the quasistatic first magnetization curves emphasizes this tendency.

It is also necessary to take into account the internal stresses in the samples. After a tensile test followed with unloading there is no macroscopic stress. However, from the shift of the position of the yield stress point after straining results an internal stress. The dislocation substructure implies that strong tension areas are counterbalanced by much larger areas of weak compression stresses [9]. Consequently, the magnetic properties along the tensile direction are on average dominated by compression effects. An internal tension stress effect does therefore exist perpendicular to the tension test direction. This could explain the increase of the degradation of the magnetic properties when magnetic tests are carried out along the tensile test direction. The internal stresses which exist in the direction of the measurements may display the same effect as an outside elastic stress [10]. The observations of the dislocations are in good agreement with this analysis : internal stresses are due to the anisotropic distribution of dislocations, clusters and tangles and both are interdependent. The anisotropic pinning/unpinning of domain walls against metallurgical defects is closely linked to the effect of anisotropic internal stresses on magnetic properties of the samples.

\section{CONCLUSION}

The strong degradation of the magnetic properties of the NO $3 \% \mathrm{SiFe}$ alloys with increasing plastic strain is the consequence of the strong pinning effect of the dislocation tangles and clusters on the magnetic domain walls. The strengthening of the material gives rise to a sensible plastic anisotropy probably linked to the strong internal stresses which are created by plastic straining. This tends to increase the magnetic degradation when magnetic tests are carried out along the tensile test direction and conversely to reduce this degradation when magnetic tests are done in the crossing direction. The effect of this plastic anisotropy on the magnetic properties could originate from two points : the pinning/unpinning of domain walls against anisotropic metallurgical defects and the anisotropic internal stresses effect on magnetic properties.

\section{References}

[1] E. Hug, O. Hubert and M. Clavel, J. Appl. Phys. 79, (1996) 4571-4573.

[2] O. Hubert and E. Hug, Mat. Sc. Techn. 11, (1995) 482-487.

[3] O. Hubert, thesis, Université de Technologie de Compiègne, 1998.

[4] A.S. Keh and S. Weissmann, «Deformation substructure in body-centered cubic metals », Electron microscopy and strength of crystals, Interscience publishers, N.Y.-London, 1963, pp 231-300.

[5] E. Hug, O. Hubert and M. Clavel, IEEE Trans. Magn. 33, (1997) 763-771.

[6] J. Lemaitre and J.L. Chaboche, Mécanique des Matériaux Solides (Dunod, Bordas, 1988), pp.196-239

[7] D.C. Jiles, Introduction to Magnetism and Magnetic Materials (Chapman \& Hall, London, 1991), pp.156-172.

[8] H.R. Hilzinger and H. Kronmüller, J. Magn. Magnetic Mat. 2, (1976) 11-17.

[9] H. Mughrabi, Acta Metall. 31, (1983) 1367-1379.

[10] K.C. Pitman, IEEE Trans. Magn. 26, (1990) 1978-1980. 